\title{
Do complexo paterno à experiência materna: repensando as "reações negativas" na clínica psicanalítica
}

\section{From the paternal complex to the maternal experience: rethinking the "negative reactions" in the psychoanalytic clinic}

\author{
Rodrigo Vieira Marques (orcid.org/0000-0002-3160-219X)'
}

\begin{abstract}
Resumo
Neste artigo, pretendemos apresentar a noção psicanalítica de reação terapêutica negativa. Parte-se das leituras de J. Rivière e J.-B. Pontalis acerca desse conceito em Freud, em particular, nas construções metapsicológicas de "O Ego e o Id", em que a noção freudiana de reação terapêutica negativa é oriunda de uma "culpa inconsciente" e de um ataque aos progressos do trabalho psicanalítico. Em seguida, discutimos algumas ideias kleinianas a esse respeito, articuladas por J. Rivière, especialmente, a recusa à introjeção em razão do medo de angústias provenientes da posição depressiva e, por conseguinte, a recusa onipotente de uma realidade psíquica. Por fim, refletimos sobre a hipótese de Pontalis da importância da "experiência materna", revivida na transferência, o que pode contribuir para ampliar a compreensão clínica dessa reação.
\end{abstract}

Palavras-chave: Reação terapêutica negativa. Complexo paterno. Experiência materna. Clínica psicanalítica.

\begin{abstract}
In this article, we intend to present the psychoanalytic notion of negative therapeutic reaction. It starts from the readings of J. Rivière and J.-B. Pontalis about this concept in Freud, in particular, in the metapsychological constructions of "The Ego and the Id", in which the Freudian notion of negative therapeutic reaction comes from an "unconscious guilt" and from an attack on the progress of psychoanalytic work. Then, we discuss some Kleinian ideas in this regard, articulated by J. Rivière, especially the refusal to introjection due to the fear of anguish arising from the depressive position and, therefore, the omnipotent refusal of a psychic reality. Finally, we reflect on the Pontalis' hypothesis of the importance of the "maternal experience", revived in the transference, which can contribute to broaden the clinical understanding of this reaction.
\end{abstract}

Keywords: Negative therapeutic reaction. Paternal complex. Maternal experience. Psychoanalytic clinic.

\footnotetext{
${ }^{1}$ Universidade Federal de Goiás, Goiânia, Brasil. E-mail: rodriggus@gmail.com.
} 


\section{A inquietante presença das "reações negativas" no processo psicanalítico: um ponto de partida}

Em geral, um processo psicanalítico tem sua origem no desejo de se encontrar um alívio para uma dor e um sofrimento psíquicos que se tornaram insuportáveis. Pensamos assim, muitas vezes, tomando a experiência médica como modelo, acreditando ser verdadeira a crença de que todo aquele que possui uma enfermidade busca o médico na expectativa de encontrar uma cura. No entanto, esse desejo pode se misturar a diversas outras motivações, muitas delas inconscientes. Pensemos em uma situação clínica.

Uma pessoa busca um psicanalista a fim de encontrar alguém que a ajude a lidar com o seu sofrimento psíquico e, como esperava, obtém êxito. Há um espaço possível e suficiente de elaboração desse sofrimento, há uma escuta continente e, mais do que isso, o reconhecimento desse êxito. Ao contrário do que se esperava, contudo, esse sucesso gera um extremo desconforto e algumas reações consideradas negativas, como desejo de interrupção ou ruptura com o processo terapêutico em curso e dificuldades de reconhecimento do trabalho e progressos realizados. Isso ocorre, especialmente, quando é percebida a iminência de se alcançar os objetivos desejados, dentre eles, uma possível mudança psíquica. Quem até então dizia não encontrar ninguém que escutasse verdadeiramente suas dores, ao encontrar, deseja romper com essa experiência. A ruptura se efetiva, pois, no instante em que esse sentimento de desconforto diante do êxito terapêutico torna-se intolerável. Pensemos um pouco nessa ambivalente situação.

Encontrando-se na experiência do "como se", entre o psicanalista-continente - tela das projeções de seu analisando - e a revivência de experiências arcaicas, na dinâmica de uma espécie de eclipse parcial, em contínuo descompasso, na busca incansável por um "objeto transformacional" (Bollas, 2009), parece-nos plausível compreender a ruptura como um contra-ataque ao que se tornara, na relação, ameaçador. A esse respeito, o significado da palavra ruptura nos é instrutiva: vem do verbo latino rumpere, que, além de romper, significa também quebrar, dilacerar, rasgar, fender, separar, traspassar, violar, infringir, arrebentar. Figurativamente, pode indicar um "estourar por despeito", perturbar o silêncio, enfraquecer. A ruptura, em suma, parece indicar uma descontinuidade, podendo expressar, com todas essas tonalidades semânticas, a verossímil situação clínica que anteriormente 
apresentamos. A tradição psicanalítica, porém, aprofunda os campos semânticos abertos etimologicamente por esse termo, oferecendo-Ihes personagens e contextos.

Neste artigo, propomo-nos a pensar, a partir de um diálogo com autores que consideramos representativos da tradição psicanalítica, algumas hipóteses metapsicológicas elaboradas na tentativa de compreensão dessas rupturas, dos sentidos construídos nessa experiência ${ }^{2}$. A reconsideração da noção freudiana de "culpa inconsciente" e o modo como ela reaparece em um modelo kleiniano (Klein 1991, 1996; Rivière, 1936) parece nos apontar outro caminho. Daí a suspeita de que essa reação possa nos levar à identificação da luta contra a presença psíquica de um "corpo estranho" (Pontalis, 2016), anterior aos conflitos estabelecidos por um "complexo paterno", e, portanto, oriundo das vicissitudes da "experiência materna" - entendida, a nosso ver, como referência a um "ambiente primitivo" e não, necessária e exclusivamente, a uma pessoa concreta.

\section{O delineamento freudiano inicial das "reações negativas": a psicanálise frente à intrigante "necessidade de doença" (Krankheitsbedürfnis)}

Como compreender, no desenrolar de um trabalho psicanalítico, aqueles que "fracassam ao triunfar", os "arruinados pelo êxito" (Die am Erfolge scheitern)? Fora o próprio Freud (1923/1967b) que nos chamara a atenção para isso em um texto de 1923, "O Ego e o Id", lembrando-nos do modo como algumas pessoas ficam descontentes quando o psicanalista lhes dá esperanças ou se sente satisfeito com o progresso do trabalho terapêutico. Essas pessoas, muitas vezes, após esse reconhecimento, apresentam pioras em seu estado. Haveria nelas uma impossibilidade não só de receber elogios, mas também de reagir positivamente ante a uma situação de progresso. Como diria Freud (1923/1967b), apresentando pioras ao invés de melhoras, é possível encontrar nessas pessoas uma "reação terapêutica negativa" (p. 278). O restabelecimento, nessa perspectiva, não só passa a ser visto como um perigo (Gefahr) a ser evitado, como também assume um papel secundário para usar uma linguagem freudiana - diante da intrigante "necessidade de doença" (Krankheitsbedürfnis).

\footnotetext{
${ }^{2} \mathrm{O}$ nosso objetivo é apresentar uma introdução a essa problemática, assim não haverá espaço para uma discussão acerca da hipótese freudiana do masoquismo primário, o que esperamos fazer em um outro trabalho.
} 
Tentando compreender essa "necessidade de doença", pensamos que é possível distinguir duas situações. Uma é aquela na qual existe uma queixa, vinda do próprio analisando na relação consigo mesmo ou com o seu ambiente, diante da qual o progresso do trabalho psicanalítico acaba por ser visto como um drama, quando, na verdade, deveria trazer uma melhora. Outra situação parecida, mas diferente, é quando a realização de um desejo "profundamente enraizado", "alimentando há muito tempo", traz inexplicavelmente uma doença. O que diferencia uma situação da outra é o desejo. Em uma, não há necessariamente o desejo de melhora. Na outra, esse desejo é fundante.

No tocante à segunda situação, já em um texto de 1916, "Alguns tipos de caráter encontrados no trabalho psicanalítico", Freud nos fala da importância de se diferenciar uma frustação externa de uma frustração interna. Logo, quando ocorre excepcionalmente um adoecimento originado de um fracasso, o que encontramos é uma frustração agindo por conta própria, uma vez que isso se dá apenas quando "a realização de um desejo" ocupou o lugar de uma "frustração externa" (Freud, 1916/1949, p. 372). Seguindo de perto a realização de um desejo, a doença assumiria o papel de impossibilitar a sua fruição, o seu gozo. Nesse texto, a dificuldade de Freud estava justamente em compreender a origem das "tendências julgadoras" e da "necessidade de punição" presente nessas experiências. Mas voltemos ao texto de 1923 e tentemos compreender essas relações mediante o vértice da segunda tópica.

Em "O Ego e o Id", podemos vislumbrar duas ideias que podem nos apontar alguns caminhos e que se encontram articuladas entre si: "a necessidade de doença" e a "reação terapêutica negativa". Ganha força, pois, a ideia de resistência e de inacessibilidade narcísica, cujos maiores obstáculos Freud identifica na "atitude negativa em relação ao médico" e no "apego ao ganho com a enfermidade". É aqui que encontramos uma noção fundamental, a proposta metapsicológica de um "sentimento inconsciente de culpa", ou em outros termos, de uma percepção existente no próprio ego que corresponderia a uma crítica engendrada e imposta pelo superego. Essa é uma definição basilar e nos traz diversas consequências.

O sentimento de culpa não indicaria necessariamente a experiência de uma responsabilidade do sujeito, em decorrência de um crime real realizado em algum momento 
de sua vida. Pelo contrário, poderia, inclusive, anteceder um crime, como acentua o texto de 1916 ao qual nos referimos. A pressão do superego se torna tão grande, principalmente por se tratar de algo não nomeado, que a concretização de um crime, seja ele qual for, poderia ser um modo de aliviar essa angústia, de lhe dar um rosto.

Para Freud, esse estrondoso e simultaneamente tácito sentimento de culpa seria a melhor expressão do superego. Em seu texto de 1916 (Freud, 1916/1949), ele parece nos levar a entender que o sintoma seria a possibilidade de aplacar esse sentimento tão invasivo, de silenciá-lo. É como se, havendo sintoma, não houvesse culpa. Afligido e torturado por uma cultura pura da pulsão de morte, em um movimento constante de autodestruição, é como se uma proteção contra o suicídio e a definitiva morte psíquica, por exemplo, fossem criadas. O ego, consequentemente, fica perdido entre o superego e o id, justamente porque o superego teria um maior conhecimento do id que o próprio ego. Como indica Freud (1923/1967b), é no ego que encontramos uma "sede real" da ansiedade, sua constante ameaça oriunda do mundo externo, da libido do id e da severidade do superego. Mas resta uma dúvida: por que o ego temeria tanto o superego ao ponto de se submeter aos seus caprichos?

No pensamento freudiano, essa consciência moral teria a sua origem no complexo de Édipo, por sua vez, inconsciente, estando nisso uma das razões do caráter inconsciente da culpa que tanto aterroriza o ego. É assim que, nesse texto de 1923, Freud não conseguia entender o medo da morte a não ser na zona de transição entre o ego e o superego, em que o ego abandonaria a si mesmo tal como abandona outros objetos quando diante de um perigo iminente e desestabilizador.

Freud entende o aparecimento do medo da morte (Todesangst) como uma reação a um perigo externo ou como um processo interno. Sobre esse último, encontramos na melancolia um exemplo eficaz. Freud entende que o que levaria na melancolia o ego a se abandonar seria o sentimento de não ser amado pelo superego, mas "odiado e perseguido". A esse respeito, vale lembrar que para o ego há uma identidade entre viver e ser amado pelo superego, o qual assumiria, por sua vez, a função de "proteger e salvar", anteriormente ocupada pelo pai, primeiramente, e posteriormente pela Providência ou mesmo pelo Destino (Freud, 1923/1967b). Desse modo, no interior do próprio id, encontramos uma luta armada 
entre Eros e pulsão de morte (Todestrieb). Aqui, diante dessa divisão no interior do próprio id, o que vislumbramos é um Eros que se apresenta como o "promotor das desordens" (Störenfried Eros), em contraposição ao projeto da pulsão de morte de tão somente "ficar em paz", de retorno ao inanimado, à ausência de movimento.

Nesse conflito, é possível encontrar, conforme indicaremos brevemente mais adiante, a constituição do que Abraham (1919/1959) denominara como "complexo paterno": a possibilidade de pensar o "medo da morte" (Todesangst) e o "medo da consciência moral" (Gewissensangst) como resultado de um conflito entre o ego e o superego, logo a partir do medo da castração (Kastrationsangst). Nesse cenário, Freud alerta para que não se desvalorize o papel de Eros ou, poderíamos dizer, de uma pulsão de vida na luta contra o desejo da pulsão de morte, por sua vez, incitada pelo princípio de prazer. Na clínica psicanalítica, contudo, encontramos subjetividades que parecem existir justamente naquilo que Ihes traz dor e sofrimento, levando-nos a pensar no predomínio das forças destrutivas da pulsão de morte. Essa situação, a nosso ver, não passara totalmente despercebida pelo pensamento freudiano.

Em “Análise terminável e interminável”, Freud (1937/1961) se perguntava se existiria algo que poderíamos chamar de término de uma análise. Segundo ele, o trabalho da análise se faz mediado por dois fatores fundamentais, a saber, o fator constitucional e o acidental. Nessa perspectiva, ao se procurar fortalecer o ego do analisando, o que se pretende é ajudálo a amansar as suas pulsões ou os efeitos de traumas muito precoces que possa ter vivido.

Acreditamos que há, na indagação sobre a possibilidade de término de uma análise, uma outra indagação oculta sobre a possibilidade de se chegar a um nível de "normalidade psíquica absoluta", um nível no qual tanto as ansiedades e as inibições do analisando foram solucionadas por inteiro e as lacunas de suas lembranças preenchidas. Tendo por referência um de seus exemplos clínicos, Freud (1937/1961) nos diz que, após um determinado período, o trabalho analítico conseguiu remover o problema trazido por sua paciente, entendida como uma "pessoa eficiente e valiosa" (tüchtigen und wertvollen Person), e restituiu os seus "direitos de participar da vida" (Rechte auf einen Anteil am Leben) (p. 66). Nessas palavras, acreditamos que nos é apresentado o principal objetivo de um trabalho psicanalítico. É provável que essa não tenha sido a intenção freudiana, ainda preocupada 
com os sucessos e fracassos na obtenção da cura, na "remoção da doença". Mas resta, sem dúvida, a profundidade de se pensar em um método de trabalho que visa, em suma, devolver ao analisando o seu "direito de participar da vida" e, sobretudo, ser a "pessoa eficiente e valiosa", proficiente e capaz de elaborar seu sofrimento psíquico.

Pensando assim, é possível falar no término da análise como o fim do compromisso que fora firmado entre psicanalista e analisando, que deixam de se encontrar como antes, e como um processo perene de reflexão e de crescimento emocional que se mantém. Nesse texto, no entanto, como já assinalamos, a intenção freudiana é a de compreender o término de uma análise como o momento em que o sintoma não cause mais sofrimento, de modo que inibições e ansiedades tenham sido superadas e o "inconsciente tornado consciente". Esse pressuposto é o que irá direcioná-lo a deslocar o foco da cura analítica para os obstáculos que se encontrariam no caminho dessa cura.

De acordo com Freud, poderíamos encontrar três fatores decisivos para o sucesso de uma análise: a influência dos traumas, a força constitucional das pulsões e as alterações do ego. No texto em questão, o seu interesse se voltou particularmente para o modo como a força das pulsões pode interferir em um processo psicanalítico. Vale salientar que o objetivo da análise não seria o de fazer com que o conflito entre as pulsões e o ego desaparecesse, até porque essa tarefa seria impossível. A meta estaria em "amansar as pulsões" de modo a colocá-las em harmonia com o ego. A "metapsicologia da Feiticeira" surgiria como tentativa de explicar o modo como essa harmonização se daria, sabendo não ser essa uma tarefa fácil, mesmo que isso seja experimentado no trabalho psicanalítico como um modo mais apaziguado de viver com os próprios conflitos, os quais não necessariamente deixam de existir.

$\mathrm{Na}$ análise, haveria a possibilidade de se reconstruir defesas mais eficazes em relação às antigas repressões, de modo que o ego não fosse mais inundado pelo excesso e pelo domínio de forças que, até então, tinham sido indevidamente reprimidas. No entanto, há de se considerar que isso se dá continuamente mediante um processo e, mais do que isso, o fato de uma nova organização ou organizações surgirem não significa que as antigas irão desaparecer, permanecendo sem alteração "partes dos antigos mecanismos" (Freud, 1937/1961, p. 73). Daí a consideração de Freud de que, se a proposta de "amansar as 
pulsões" pode ser correta na teoria, o mesmo nem sempre se dá na prática, e a razão se encontra no simples fato de que nada adiantará um ego fortalecido se a força das pulsões for excessiva, pois não é possível uma transformação completa de nossos mecanismos defensivos. Além disso, um novo incidente profundamente traumático pode mobilizar antigos conflitos, sem considerar o fato de que os analisandos não conseguem trazer todos os seus conflitos para a relação transferencial, nem o psicanalista antecipar possíveis conflitos de seus analisandos, pois mesmo sendo possíveis de serem imaginados, só fazem sentido quando vividos. Para Freud, o sucesso de uma análise se dá, em particular, quando o psicanalista consegue se aliar ao ego do analisando a fim de incluir, nesse mesmo ego, "as partes não controladas do id". Desse modo, as mudanças do ego podem ser congênitas e/ou adquiridas, e é sobre estas últimas que o trabalho psicanalítico costuma ter mais êxito.

No pensamento freudiano, as alterações do ego vão sendo adquiridas ao longo da vida, procurando sempre mediar as relações entre seu id e o mundo externo. A educação acaba cumprindo a função de levar o ego a considerar também o id como perigoso ao trazer o conflito de fora para dentro. Por isso os mecanismos de defesa surgem e assumem a tarefa de evitar tudo o que for entendido como perigo, inclusive a ansiedade e o desprazer. Quanto a isso, entretanto, é importante salientar que se há algo que o aparelho psíquico não tolera, sem protesto, é o desprazer, mesmo que seja preciso deformar a percepção da realidade, apresentando como inimigo todos aqueles que possam ameaçar a realização do princípio de prazer, o qual encontra um forte aliado na pulsão de morte.

$\mathrm{Na}$ tentativa de proteger o ego desses inimigos, os mecanismos de defesa utilizados ao longo da vida dificilmente são abandonados, e cada um faz uma seleção particular daqueles que melhor se harmonizam com a sua própria personalidade. O problema é que, mesmo adulto, é possível que o ego continue a se defender contra os perigos com os quais se defrontou em um período anterior. A força desses mecanismos é tão grande que, se for preciso, uma busca por perigos que possam se assemelhar ao perigo original é iniciada, pois o que se procura é justificar o uso de tais defesas bem como a sua manutenção.

Embora cumpra a função de proteger o ego, os seus mecanismos de defesa podem distanciá-lo também do mundo externo e gerar adoecimento. Com efeito, como isso se relaciona com o trabalho psicanalítico? Esses padrões de defesa ocorrem também na análise, 
sendo essa repetição o que justamente nos permite conhecê-los, o que leva Freud (1937/1961) a considerar que a análise se desenvolve mediante um pêndulo que oscila entre um "fragmento de análise do id" e um "fragmento de análise do ego" (p. 84). A dificuldade, porém, surge quando a defesa dirigida a um perigo original reaparece, no trabalho psicanalítico, contra o próprio desenvolvimento do analisando. Desse modo, quando conflitos defensivos são acionados, 0 analisando se vê inundado por impulsos desprazerosos, o que possibilita o surgimento de "transferências negativas" (negative Übertragungen). Na luta contra esse insuportável desconforto, o analista se torna um estranho que nada mais faz senão lhe "fazer exigências desagradáveis", e o analisando volta a ser uma "criança que não gosta do estranho e não acredita em nada do que ele diz" (Freud, $1937 / 1961$, p. 85).

Nesses movimentos, podemos encontrar os elementos que estarão presentes na formação de uma reação terapêutica negativa. Pensando nessas questões, Joan Rivière, em sua leitura das últimas páginas de "O Ego e o Id", entenderá essa reação, em um primeiro momento, como "[...] uma condição que, em última instância, impede uma análise e a torna impossível; a expressão é constantemente usada no sentido de não analisável" (Rivière, 1936, p. 304). Todavia, ao repensar o modo como Freud compreende os "arruinados pelo êxito" seguindo as trilhas de Klein, a autora percebe que não há uma constatação de não analisabilidade, mas de pessoas que se encontram em uma situação de sofrimento.

Apesar do reconhecimento de que isso venha a se constituir um obstáculo ao trabalho analítico, nota-se, nos horizontes kleinianos seguidos por Rivière (1936), que não se trata de algo definitivo, o que a levou a concluir que Freud não seria tão pessimista como se costuma imaginar. Falar em reação terapêutica negativa significaria justamente se referir aos analisandos que não conseguem se beneficiar da análise ou, no caso de Freud, aos “pacientes psicóticos ou 'narcisistas'”, considerados por ele impossibilitados de um trabalho psicanalítico. A constatação freudiana é de que o superego desses analisandos possui uma força tão intensa que é capaz de destruir o que viesse a ser construído em análise.

A razão dessa impossibilidade talvez esteja na radicalização, seguida inicialmente "em partes" pela tradição psicanalítica - haja vista os tácitos e inovadores questionamentos de Abraham (1919/1959) a esse respeito - da distinção entre as neuroses de transferência 
e as neuroses narcisistas. Na história da psicanálise, acreditamos que os desdobramentos do pensamento kleiniano tenham possibilitado, ao repensar os horizontes desse dualismo, o desenvolvimento de um trabalho também com esses analisandos, hoje considerados, a nosso ver, com um sofrimento psíquico preponderantemente psicótico ou limítrofe. É assim que, para Rivière (1936), a partir dos trabalhos de Klein, é possível identificar outros fatores presentes nas tentativas de destruição do que é construído no processo psicanalítico. A seguir, pensemos nessas questões.

\section{Rivière e a tradição kleiniana: as resistências narcísicas como medo da culpa}

Rivière (1936) considera as "neuroses narcísicas", nas trilhas de Abraham (1919/1959), como "perturbações de caráter". No caso das "neuroses de transferência", é possível observar como o superego vai sendo aos poucos mitigado "pelo sentimento de culpa" e pelos "sintomas". Todavia, quando se trata das "neuroses narcísicas", pensando nos mecanismos de projeção, na ideia de um mundo que é visto como posicionado contra o sujeito, observa-se que o superego, de fato, jamais chegara a ser aplacado de modo suficiente. O problema surge quando o trabalho psicanalítico busca justamente levar o analisando a um processo de introjeção, a perceber que as "circunstâncias" do mundo não estiveram necessariamente contra ele, mas houve, de sua parte, uma participação nessa compreensão de mundo.

Chegamos, pois, usando uma expressão de Meltzer (1971), ao "umbral da posição depressiva". Nesse ponto é que Rivière (1936) nos apresenta uma interessante hipótese: com o decorrer da análise, ao se dar conta de que também tivera uma participação no sentido dado às suas próprias experiências emocionais, o analisando desenvolve o sentimento de que deveria ser punido por isso, nem que seja adoecendo. Em sua fantasia inconsciente, a continuidade com o trabalho psicanalítico poderia, inclusive, agravar essa punição. No entender de Rivière (1936), embora haja em toda situação clínica motivos favoráveis ou desfavoráveis à cooperação, quando se trata de analisandos com perturbações de caráter, essas mesmas perturbações podem assumir uma "força peculiar" (p. 306). 
Procurando compreender melhor o que seria essa "força peculiar" presente nesses casos, Rivière recorre ao que Abraham (1919/1959) denomina "tipo narcísico de resistência de caráter". Essa ideia se encontra melhor articulada em um texto intitulado "Uma particular forma de resistência neurótica contra o método psicanalítico". Nesse texto, Abraham nota, apesar de aparentemente simples, o quão complexo é para alguns analisandos se permitirem a experiência da associação livre. Haveria uma resistência a fim de impedir que algumas coisas pudessem se tornar conscientes, e, ao se tornar crônica, resultaria no impedimento do próprio acompanhamento psicanalítico. Esses analisandos assumem a tarefa de impedir também a fala do psicanalista. Constroem ao redor de si mesmos uma muralha de palavras, porém, com tijolos muito bem selecionados e conforme uma programação muito bem definida. O que chama a atenção é que, apesar disso, apresentam uma aparente boa vontade, e uma "incansável disposição à análise".

É considerando essa disposição que Abraham salienta o modo como o "complexo paterno" interfere nessa relação. Apesar da grande quantidade de material que apresentam ao psicanalista, o que é apresentado por esses analisandos é apenas aquilo que não "fira o seu amor-próprio", haja vista serem muito intolerantes e sensíveis a qualquer coisa que possa fazê-los se sentir humilhados. A análise se converte em um espaço onde o desprazer não encontra lugar. Esse aspecto infantil da personalidade é muito bem expresso no exemplo que Abraham (1919/1959) nos dá dos motivos que podem levar uma criança a querer usar óculos. Não se trata da possibilidade de enxergar melhor, mas de poder exibilos na escola. Trazendo o exemplo para a experiência clínica, o que se nota é que a análise assume primeiramente um propósito narcisista.

O que esses analisandos buscam, muitas vezes, é descobrir que espaço possuem na mente de seu psicanalista, qual o seu valor afetivo em relação aos demais analisandos, precisando constantemente reafirmar uma "necessidade de amor narcisista". Aqui Abraham nos traça uma diferença muito importante para a psicanálise contemporânea, embora siga a distinção feita por Freud - não rompendo radicalmente com ela - entre "neuroses narcisistas" e "neuroses de transferência". Para Abraham (1919/1959), a diferença estaria em que, nas "neuroses narcisistas", "ao invés de fazer uma transferência, os pacientes tendem a 
se identificar com o médico. Ao invés de travar com ele uma relação mais estreita, colocamse em seu lugar" (p. 233).

Metaforicamente, agem como uma criança que brinca de se colocar no lugar do pai. Assim, há um desejo de superar o psicanalista, procurando frequentemente travar com ele um embate argumentativo, ao invés da abertura a uma experiência emocional. Observando esse modo de agir, Abraham percebe a presença da inveja e o modo como ela emperra o trabalho. Em razão disso, o analisando procura ocultar, em suas falas, todo e qualquer acontecimento que possa demonstrar que ele esteja se beneficiando do trabalho analítico, pois o seu esforço é o de provar para si mesmo e para o psicanalista que não precisa da ajuda de ninguém, que consegue se construir sozinho. É assim que surge a ideia de um poder absoluto de "autoanálise", experiência que Abraham considera como um "sonho diurno", um substituto muito justificado e até mesmo prescrito da masturbação.

No entanto, é na identificação de um traço anal-sádico presente nesses analisandos que talvez se encontre a maior contribuição de Abraham. Para esses analisandos, as palavras passam a ser vividas principalmente como excrementos, considerando que o material psíquico é expelido tal como a evacuação do intestino. É interessante notar nisso o prazer em poder decidir em que momento, em que quantidade e de que modo irão expelir o material inconsciente, ou mesmo, em poder fingir, tal como algumas crianças, que estão liberando algum excremento, quando na verdade nada está acontecendo. Isso explicaria, como lembra Abraham ao retomar Freud, porque tais analisandos possuem uma predisposição a dar presentes ao invés de amor. O investimento na análise, por sua vez, torna-se possível como um sacrifício em prol de seu próprio narcisismo, dos ganhos secundários que essa experiência poderá trazer.

Partindo dessas considerações de Abraham, Rivière se centra no modo como todas essas disposições, presentes em alguns analisandos, servem de impedimento ao desenvolvimento de uma "associação livre" no trabalho psicanalítico. Tanto para Rivière como para Abraham, como já vimos, o material apresentado ao psicanalista é cuidadosamente selecionado, até mesmo como uma maneira eficaz de decepcioná-lo ao ser negada a proposta de uma fala "livre". Desse modo, trazem apenas o que consideram ser os seus aspectos bons, tiram o psicanalista de sua posição e se escondem atrás de uma 
"máscara de polida afabilidade e racionalização", uma máscara que oculta, todavia, uma postura de crueldade, de pessoas muito "satisfeitas consigo mesmas" e "desafiadoras", uma "máscara de submissão" (mask of compliance) que Abraham relacionou muito bem, conforme já dito, com uma "onipotência anal" (Rivière, 1936, p. 306).

Mas parece-nos que uma importante conclusão que Rivière retirara de sua leitura de Abraham é que, quando se trata de analisandos "refratários", de "difícil acesso", o que encontramos na verdade são "resistências narcísicas". Partindo desse pressuposto, dizer que o narcisismo possa ser a "raiz do problema" nesses casos parece indicar o retorno a um certo postulado freudiano. Embora não seja nova a ideia de que o narcisismo parta de uma retirada da libido de um objeto externo a fim de direcioná-la ao próprio ego, Rivière inova ao tentar pensar esse problema a partir dos trabalhos de Klein, ou seja, das relações de objeto, dos objetos que foram internalizados pelo ego.

Por conseguinte, Rivière (1936), partindo de sua leitura do pensamento kleiniano, salienta o fato de que "o elemento essencial da atitude maníaca é a onipotência e a recusa onipotente da realidade psíquica, o que leva, é claro, a uma percepção distorcida e defeituosa da realidade externa" (p. 308). Essa recusa pode ser compreendida no desejo de controle como tentativa de se evitar a angústia de introjetar o que de bom é apresentado pela análise. Nesse sentido, a introjeção é sempre vivida de maneira aterradora, lembrando que o medo não é diretamente da posição depressiva, mas da percepção que a antecede, a saber, o reconhecimento do analisando de seus próprios enganos e fracassos. Se a vivência da angústia causa tanto terror, a experiência da culpa só pode ser projetada, recusada ou racionalizada, fazendo da relação com o psicanalista a revivência de um seio persecutoriamente mau.

Para esses analisandos, o controle e a recusa de toda e qualquer culpa diante dos danos causados a seus objetos é a possibilidade de viver em um mundo "suportável", o mesmo mundo que se torna ameaçado em um processo psicanalítico. No entanto, a mudança não apenas se torna insuportável por representar uma perda de controle, mas há também a crença de que toda e qualquer melhoria é impossível. Não só há um desejo de não melhoria, mas de que um "pior aconteça", acreditando que suas fantasias possam se tornar reais com o desenvolvimento do processo psicanalítico. 
Procurando pensar essas situações clínicas, Rivière (1936) nos assinala que podemos entender as "negações onipotentes" desses analisandos em razão da "verdade psíquica" de que, em sua história, realmente terríveis desastres aconteceram. O reconhecimento dessa verdade vem acompanhada de muita angústia, do sentimento de que poderiam não sobreviver ante a possibilidade de uma morte iminente e incontornável enlouquecimento. As "angústias depressivas" precisam se manter congeladas, pois a sua mobilidade poderia suscitar uma realidade interna fragmentada, uma terra desolada, habitada por fantasmas, onde o amor não possui cidadania. No instante em que vai se aproximando o predomínio de uma posição depressiva, como diria Klein, vai surgindo também a possibilidade da passagem da lida com objetos parciais para o convívio com objetos totais; em outras palavras, esses analisandos vão conseguindo perceber e aceitar a ambivalência de seus objetos.

O problema é que a introjeção de objetos totais, sendo capaz de mitigar o "ódio" ante uma história de profundas frustrações, traz também sentimentos de culpa e de arrependimento. Para alguns, todavia, quanto maior o ódio, maior o sentimento de que o "amor está morto" e a cristalização de um mundo interno que se assemelha a um cemitério, com a ressalva de ser habitado por "perseguidores imortais", pelo sentimento de que nada possa reparar os "assassinatos psíquicos" cometidos por um superego cruel. É assim que, à medida que a análise vai caminhando, os conflitos vividos com tantos personagens trazidos para as sessões vão se tornando um conflito vivido na relação do analisando consigo mesmo, com seu próprio modo de funcionamento. Ao perceber que o processo psicanalítico possibilitara trazer à luz um mundo interno povoado por "objetos zumbis", com os quais se encontra identificado - daí os constantes sentimentos de morte ou de enlouquecimento -, qual seria a razão de o analisando não decidir partir em busca de um abrigo? Por que não interromper um processo que mais se assemelha à abertura de um catastrófico "juízo final"?

Um dos ensinamentos do pensamento kleiniano certamente é que o desenvolvimento de uma posição depressiva pressupõe, sobretudo, tolerância em reconhecer o próprios enganos e fracassos. Bion (1957/1966) poderia acrescentar a isso não só tolerância, mas a capacidade de aprender com esses enganos. O difícil é que, para alguns analisandos, especialmente aqueles com sofrimentos narcísicos intensos, reconhecer o engano é o 
mesmo que se entregar aos braços da morte, tal como fizera o próprio Narciso ante a imagem de si mesmo. Nesse contexto, como aprendemos com Rivière (1936), as relações de objeto, no final das contas, são partes constitutivas do próprio narcisismo.

Desse modo, por um lado, esses analisandos parecem tentar, em um plano consciente, lidar melhor com seus dramas e se livrar de seus sintomas. Por outro lado, dão mostras de cultivar inconscientemente o desejo ou mesmo a necessidade de se evitar uma desintegração e uma morte iminentes, daí a busca de restauração de seus objetos internos, os quais para eles passam a constituir o único mundo existente. É assim que a sua atitude autorreferida se torna referência a um mundo interno que, mediante um processo de cisão, acabou se convertendo no "mundo inteiro". Consequentemente,

[...] é o amor por seus objetos internos que está subjacente e produz a insuportável culpa e a dor, a necessidade de sacrificar sua vida por eles, e aí então é a perspectiva da morte o que faz esta resistência ser tão obstinada. (Rivière, 1936, p. 319)

Ora, retornando ao pensamento freudiano, compreendemos melhor essas resistências quando não nos esquecemos do fato de que originariamente id e ego eram um só. Essa relação pode nos aclarar a consideração de que os empecilhos que impedem o ego de se desenvolver se encontram em raízes mais profundas. Isso se esclarece principalmente quando consideramos estar em operação nessas raízes - juntamente com as complexas relações entre id, ego e superego - as forças de vida e de morte; a maneira como, permeando as diferentes instâncias psíquicas, essas forças se distribuem, se misturam e deixam de estar fundidas [Triebentmischung].

Assim sendo, conforme vimos, no sentimento de culpa que conduz a uma necessidade de punição, podemos encontrar a presença de uma força que se coloca contra os benefícios que poderiam ser trazidos pelos progressos do trabalho psicanalítico. Inicialmente, Freud identifica essa força na relação existente entre o ego e o superego, no entanto, reconhece também a possibilidade da presença não só do princípio de prazer, mas também da pulsão de morte. Compreendemos melhor os fenômenos da vida, assinala Freud (1937/1961), pela relação primitiva e complementar de pulsões destrutivas e de pulsões de vida. 
Essas ideias permitiram a Rivière aprofundar o modo como essas forças se encontram articuladas na impossibilidade de alguns analisandos internalizarem o que de bom lhes é oferecido pela experiência psicanalítica. Seguindo essa discussão, entretanto, é interessante notar como o diálogo com essas mesmas concepções freudianas estiveram presentes na investigação de Pontalis (2016) sobre a reação terapêutica negativa, conduzindo-o também a diferentes conclusões. O desdobramento do próprio conceito metapsicológico do sentimento inconsciente de culpa parece ter nos distanciado de uma compreensão das "reações negativas" em relação ao trabalho psicanalítico nos contornos de um "complexo paterno", sejam as ideias de resistência no cenário do medo da castração, representado pelas lutas entre ego e superego (Freud), seja na encenação da inveja como defesa frente a uma ferida narcísica (Abraham). Longe disso, essas reações podem acenar, conforme veremos na leitura que Pontalis fará de Rivière, a "internalização de um objeto estranho", de tal modo ameaçador e persecutório, que a ruptura com qualquer pessoa que represente essa experiência tão terrível ou com situações que lhe façam revivê-la passe a ser, em contrapartida, um movimento de vida.

\section{A compreensão da reação terapêutica negativa na passagem do "complexo paterno" à "experiência materna": a luta contra o “corpo estranho"}

Pontalis (2016) parece propor uma releitura de "O Ego e o Id" a partir da passagem de um "complexo paterno", celebrado especialmente nos desdobramentos do Édipo para uma "experiência materna". Os analisandos de difícil acesso seriam aqueles que, pobres de lembranças de sua infância, seriam conduzidos "[...] principalmente por palavras ou expressões proferidas com mais frequência pela mãe" (Pontalis, 2016, p. 255). A grande questão é que essas palavras são dotadas de um grande poder, investidas semanticamente como atos, "são vividas como vereditos irrevogáveis, decretos recebidos como recusa de justiça, e não suscetíveis de qualquer espécie de modificação que as relativizaria ou, o mais importante, relativizaria a imagem e o poder da pessoa que as expressou" (Pontalis, 2016, p. 255). Nesse contexto, em razão do caráter absoluto adquirido pelas palavras maternas, a reação seria, naturalmente, a única resposta possível, nem que seja mediante atuações ou 
somatizações. Por conseguinte, algo semelhante passa a ocorrer na relação psicanalítica, o que configura, como indica Pontalis (2016), uma relação transferencial "extremamente intensa", sem meio-termo ou nuance, "[...] esticada ao extremo, esticada a ponto de se romper, com flutuações repentinas, violentas, de sentimentos: admiração e desprezo, gratidão e rejeição. Tudo branco ou preto" (p. 255).

Pontalis pensa a reação terapêutica negativa, de paralização e de ruptura da parte de alguns analisandos, como uma reação a essa mãe - e, poderíamos acrescentar, a um ambiente primitivo aterrador - que trazem dentro de si e com a qual primitivamente se identificaram. Aqui parece estar falando do modo como esse sentimento de culpa foi tomado "emprestado" dessa figura materna. À vista disso, na situação analítica, não é possível haver troca, mas uma relação de dominação, de controle, de luta entre um forte e um fraco, haja vista que "[...] a força motivadora por trás da reação terapêutica negativa é a paixão louca por mudar, por curar a mãe louca dentro de si" (Pontalis, 2016, p. 256). Nessa perspectiva, paradoxalmente, é importante notar que a recusa ao psicanalista pode ser também um movimento de vida, é o desejo de curar uma mãe louca outrora introjetada e que no presente funciona como um corpo estranho, um impedimento à experiência do gozo, à busca da jouissance, dado que isso só é permitido a essa mãe, dotada de um poder absoluto.

Certamente aqui cabe a consideração de que "na introjeção primária do 'mau' há o desejo de se apropriar e controlar o estranho; o sujeito faz seu o que, por natureza the escapa; come o desconhecido (e então, se faz devorar por ele)" (Pontalis, 2016, p. 262). Como então ouvir o psicanalista quando ele passa a ocupar transferencialmente o papel dessa mãe? Como dirá Pontalis (2016, p. 257), “indestrutível, o objeto mau garante ao sujeito sua permanência". Falando de como isso se manifesta em seu analisando - e que valeria também para muitos de nossos analisandos - ele não nos fala de um processo de identificação por considerar ser um termo muito fraco para traduzir essa experiência, mas “[...] de possessão por um corpo estranho interno que constantemente intrusivo, implacavelmente violento, exerce seu domínio a partir de dentro, como se a mãe fosse um substituto da pulsão" (Pontalis, 2016, p. 257). 
A experiência de ser possuído por um "corpo estranho", por consequência, gera o violento esforço de não só controlá-lo, mas também de expulsá-lo. Ao pensar nesse exercício de controle, Pontalis se recorda da noção freudiana de "pulsão de dominação" ou "pulsão de apoderamento" (Bemächtigungstrieb) sobre a qual ele irá propor uma compreensão diferente. Antes, porém, vale lembrar que o termo "pulsão de dominação" aparece em Freud já nos Três Ensaios sobre a Teoria da Sexualidade, estabelecendo relação com um "aparelho de dominação" (Bemächtigungsapparat) em que, embora mesclado à pulsão sexual, pertenceria antes a uma organização pré-genital, a experiências mais primitivas. Apesar de prévio à fase genital, Freud estabelece inicialmente uma relação entre a "pulsão de dominação" e a sexualidade a partir da noção de sadismo, no desejo de subjugar o outro (Freud, 1905/1968). Essa pulsão, contudo, vai perdendo espaço na obra freudiana, pautada por um modelo biológico, para a oposição entre "pulsões de autoconservação" e "pulsões sexuais", aparecendo quase como que um intermediário entre esses dois componentes, dada a sua não oposição à esfera sexual.

No entanto, a partir de 1920, a "pulsão de dominação" acaba se tornando apenas um derivado da pulsão de morte, haja vista a instauração do dualismo freudiano entre os reinos de Eros e de Thanatos, em particular, nas vicissitudes do "além" do "Além do Princípio de Prazer". É assim que, no clássico exemplo do carretel, na tentativa da criança em controlar as idas e vindas da mãe, o que encontramos é também o desejo de se vingar do afastamento materno, de expressar um impulso de hostilidade (Freud, 1920/1967a). Essa dominação simbólica do objeto, entretanto, como ressaltarão Laplanche e Pontalis (2001, p. 400), “[...] é paralela à ligação entre a lembrança traumática e a energia que a investe". A razão disso está na guinada freudiana dos anos de 1920, quando a ideia de dominação vai perdendo espaço para a ideia de destrutividade, deixando de estar ligada a uma pulsão em específico. A "pulsão de dominação" se torna uma das formas que "[...] a pulsão de morte pode tomar quando 'entra a serviço' da pulsão sexual” (Laplanche \& Pontalis, 2001, p. 400). O que faria então a "pulsão de dominação" parecer não sexual?

Conforme a hipótese de Pontalis (2016), o que nos leva a considerar a "pulsão de dominação" como não sexual possivelmente seria o fato de a pulsão sexual ter sido, em suas palavras, "confiscada pelo objeto interno prevalente". A reação, entendida como única 
possibilidade de sobrevivência desses analisandos frente a vivência de um "corpo estranho" tão ameaçador, ocorre pelo fato de esse mesmo corpo, desse "excesso de mãe em si", ter assumido uma potência absoluta. Dessa maneira, a reação terapêutica negativa se converte no sinal de que o organismo está vivo, haja vista ser uma reação salutar, um sinal de luta, de bravura, de desejo de viver. Separar-se das palavras do psicanalista, nesse contexto, pode ser uma tentativa de se separar dessa mãe terrível existente dentro de si, mesmo que essa constatação possa não agradar muito ao que houver de não suficientemente elaborado no narcisismo desse mesmo psicanalista. Aqui, o desejo psicanalítico de cura não deixa de ser uma espécie de formação reativa. A negatividade pode ser um desejo de viver, a busca por um novo nascimento quando, na impossibilidade da simbolização, a validade de uma mudança só faz sentido quando concretizada em uma realidade externa. Logo, conforme continua nos assinalando Pontalis (2016, p. 263),

Não há razão para invocarmos, mais do que Freud, a reação terapêutica negativa para justificar todas as nossas falhas e decepções. Cada um ama sua neurose, e muito frequentemente só é amado por ela, essa neurose que consiste da recusa da insatisfação e que não admite a desilusão do amor. Cada um de nós a prefere, em todo caso... ao restante. O que vislumbro aqui é de outra ordem. Não se trata mais de inércia, mas de uma força, sofrida e exercida: o domínio do "não".

Como é possível concluir do que foi dito, a recusa à análise pode ser entendida, então, como resistência. No entanto, lembra Pontalis (2016), reação, resistência, "[...] dessa vez, no sentido vital, quase heroico do termo, diante de alguém que afirma estar meramente empenhado no nosso bem-estar, enquanto tudo o que solicitamos é respirar livremente" ( $p$. 216). Seria isso deixarmos o nosso ofício de psicanalista - entendendo por isso a busca de compreensão do mundo interno de nossos analisandos - e partirmos para o reconhecimento de um primado do mundo externo? Será que ainda tem sentido essa oposição tão radical? O nosso ofício poderia se resumir apenas à leitura desse mundo interno, mesmo quando se assume a tarefa de compreendê-lo, em estado nascente, conforme vimos inicialmente, na relação transferencial com o próprio psicanalista?

Se as primeiras e fundantes experiências do analisando foram, terrível e indelevelmente, a de internalização de uma mãe psicótica, desorganizada, é possível supor 
que "muito pouco" poderia ser feito pelo trabalho psicanalítico. Quanto a isso, vale dizer, "pouco" para a nossa teoria, mas tão imenso nas configurações e possibilidades de seu continente psíquico. Ao rompermos com o nosso vício em considerarmos sempre e exclusivamente o analisando sob a ótica de suas projeções e participação em um teatro unicamente interno, talvez seja possível descobrirmos que não há possibilidade de um ser adquirir existência, tornar-se vivo, encontrando-se desancorado de uma mãe/ambiente suficientemente bom. Essa ideia futuramente pode nos conduzir a um diálogo com os trabalhos de Sándor Ferenczi e de D. W. Winnicott, o que não seria possível nos limites desse artigo. Como consequência disso, precisaríamos também romper com o maniqueísmo dos objetos bons e maus, e nos aproximarmos do que, na vida desse mesmo analisando, foi vivido como aquilo que, em um determinado instante, Ihe foi suficiente.

\section{Considerações finais}

Dessas considerações, rompendo com um modelo médico de cura, podemos notar a possibilidade de estabelecer uma relação entre a noção freudiana de culpa inconsciente, ampliada pelo pensamento kleiniano, e a ideia de internalização de um "objeto estranho", proposta por Pontalis. Nossa compreensão da reação terapêutica negativa passa a ser outra quando consideramos a ruptura mediante a possível revivência de uma experiência muito mais primitiva, no instante em que o estranho (Das Unheimliche) nos revela algo que um dia nos foi excessivamente familiar. Se nisso há algum sentido, é possível considerar que, de certo modo, um processo de elaboração emocional pode acontecer também nos casos de ruptura com o trabalho psicanalítico, ou antes, que a ruptura faz igualmente parte desse processo.

Considerando isso, o que surge de reação terapêutica negativa pode ter sido aquilo que fugiu do "envelope" (Pontalis, 2016) da relação analista-analisando. Seria essa hipótese verossímil? Não seria reconhecer, em alguns casos, a impossibilidade da própria psicanálise? Em nossa compreensão do trabalho psicanalítico, longe do arroubo megalomaníaco de uma ciência absoluta, é certo que sim. Todavia, ao se mostrar o que há de vida na "reação", é possível que Pontalis (2016) esteja também nos tentando mostrar um outro vértice dessa 
problemática, aquele que nos leva a considerar a positividade que há no negativo. Mudando o nosso olhar sobre o que está em jogo nessa "reação", descobrindo novos vértices, talvez possamos lidar melhor, clinicamente, com essa experiência.

\section{Referências}

Abraham, K. (1959). Una forma particular de resistencia neurótica contra el método psicoanalítico. In K. Abraham, Psicoanálisis Clínico (pp. 231-237). Buenos Aires: Ediciones Hormé. (Obra original publicada em 1919)

Bion, W. R. (1966). Aprendiendo de la experiencia. Buenos Aires: Editorial Paidos. (Obra original publicada em 1957)

Bollas, C. (2009). La sombra del objeto: Psicoanálisis de lo sabido no pensado. Buenos Aires: Amorrotu.

Freud, S. (1967a). Jenseits des Lustprinzips. In S. Freud, Gesammelte Werke (v. 13, pp. $01-$ 69). Rio de Janeiro: Imago. (Obra original publicada em 1920)

Freud, S. (1949). Einige Charaktertypen ans der psychoanalytischen Arbeit. In S. Freud, Gesammelte Werke (v. 10, pp. 363-391). London: Imago. (Obra original publicada em 1916)

Freud, S. (1961). Die endliche und die unendliche Analyse. In S. Freud, Gesammelte Werke (v. 16, pp. 57-99). London: Imago. (Obra original publicada em 1937)

Freud, S. (1967b). Das Ich und das Es. In S. Freud, Gesammelte Werke (v. 13, pp. 235-289). London: Imago. (Obra original publicada em 1923)

Freud, S. (1968). Drei Abhandlungen zur Sexualtheorie. In S. Freud, Gesammelte Werke (v. 5, pp. 27-145). London: Imago. (Obra original publicada em 1905)

Klein, M. (1996). Amor, culpa e reparação e outros trabalhos (1921-1945). Rio de Janeiro: Imago.

Klein, M. (1991). Inveja e gratidão e outros trabalhos (1946-1963). Rio de Janeiro: Imago.

Laplanche, J., \& Pontalis, J.-B. (2001). Vocabulário de psicanálise. São Paulo: Martins Fontes.

Meltzer, D. (1971). O processo psicanalítico: da criança ao adulto. Rio de Janeiro: Imago. 
Pontalis, J.-B. (2016). Não, duas vezes não: tentativa de definir e desativar a "reação terapêutica negativa". Livro Anual de Psicanálise, XXX(2), 247-266.

Rivière, J. (1936). A contribution to the Analysis of the Negative Therapeutic Reaction. The International Journal of Psychoanalysis, 17, 304-320.

Recebido em: 15/7/2018

Aprovado em: 8/4/2019 